\title{
Lateral release associated with MPFL reconstruction in patients with acute patellar dislocation
}

\author{
Nadim Kheir ${ }^{1 \dagger}$, Giuseppe Salvatore ${ }^{2 \dagger}$, Alessandra Berton ${ }^{2 \dagger}$, Alexander Orsi ${ }^{3}$, Jonathan Egan ${ }^{1}$, Amin Mohamadi ${ }^{1}$, \\ Joseph P. DeAngelis ${ }^{4}$, Arun J. Ramappa ${ }^{4}$, Umile Giuseppe Longo ${ }^{2 \dagger}$, Vincenzo Denaro ${ }^{2 \dagger}$ and Ara Nazarian ${ }^{1,5^{*+}}$
}

\begin{abstract}
Objective: Medial patellofemoral ligament (MPFL) injury occurs in the majority of the cases of acute patellar dislocation. The role of concomitant lateral retinaculum release with MPFL reconstruction is not clearly understood. Even though the lateral retinaculum plays a role in both medial and lateral patellofemoral joint stability in MPFL intact knees, studies have shown mixed clinical outcomes following its release during MPFL reconstruction surgery. Better understanding of the biomechanical effects of the release of the lateral retinaculum during MPFL reconstruction is warranted. We hypothesize that performing a lateral release concurrent with MPFL reconstruction will disrupt the patellofemoral joint biomechanics and result in lateral patellar instability.
\end{abstract}

Methods: A previously developed and validated finite element (FE) model of the patellofemoral joint was used to understand the effect of lateral retinaculum release following MPFL reconstruction. Contact pressure (CP), contact area (CA) and lateral patellar displacement were recorded. abstract.

Results: FE modeling and analysis demonstrated that lateral retinacular release following MPFL reconstruction with tibial tuberosity-tibial groove distance (TT-TG) of $12 \mathrm{~mm}$ resulted in a 39\% decrease in CP, 44\% decrease in CA and a $20 \%$ increase in lateral patellar displacement when compared to a knee with an intact MPFL. In addition, there was a $45 \%$ decrease in $\mathrm{CP}, 44 \%$ decrease in CA and a 21\% increase in lateral displacement when compared to a knee that only had an MPFL reconstruction.

Conclusion: This FE-based analysis exhibits that concomitant lateral retinaculum release with MPFL reconstruction results in decreased PF CA, CP and increased lateral patellar displacement with increased knee flexion, which may increase the risk of patellar instability.

\footnotetext{
*Correspondence: anazaria@bidmc.harvard.edu

${ }^{\dagger}$ Nadim Kheir, Giuseppe Salvatore and Alessandra Berton contributed equally to this work.

†Umile Giuseppe Longo, Vincenzo Denaro and Ara Nazarian contributed equally as senior authors.

${ }^{1}$ Musculoskeletal Translational Innovation Initiative, Carl J. Shapiro Department of Orthopaedic Surgery, Beth Israel Deaconess Medical Center, Harvard Medical School, Boston, MA, USA

Full list of author information is available at the end of the article
}

\begin{abstract}
Introduction
Acute patellar dislocations primarily occur in active young patients [1], with a recurrence rate of $17 \%$ after the first dislocation episode and up to $49 \%$ after recurrent dislocations [2]. Injury to the medial patellofemoral ligament (MPFL) can be seen in the majority of cases after initial patellar dislocation [3-7]. MPFL is responsible for up to $60 \%$ of the restraining force against lateral patellar dislocation [8]. Thus, many authors have advocated for acute treatment of the medial patellofemoral ligament (MPFL) after a first-time patellar dislocation [9-11].
\end{abstract} original author(s) and the source, provide a link to the Creative Commons licence, and indicate if changes were made. The images or other third party material in this article are included in the article's Creative Commons licence, unless indicated otherwise in a credit line to the material. If material is not included in the article's Creative Commons licence and your intended use is not permitted by statutory regulation or exceeds the permitted use, you will need to obtain permission directly from the copyright holder. To view a copy of this licence, visit http://creativecommons.org/licenses/by/4.0/. The Creative Commons Public Domain Dedication waiver (http://creativeco mmons.org/publicdomain/zero/1.0/) applies to the data made available in this article, unless otherwise stated in a credit line to the data. 
Depending on the extent of injury of the MPFL, primary repair or reconstruction of the MPFL is advocated. In most cases where MPFL reconstruction is warranted, lateral retinacular release is performed at the time of surgery $[6,9,11-14]$. The lateral retinaculum is a complex structure composed of various fascial layers on the anterolateral aspect of the joint [15]. The lateral retinaculum has been proven to affect both medial and lateral patellofemoral joint stability in knees with an intact MPFL [16]. Biomechanical studies on isolated lateral release drive to the conclusion that it should not be performed as a primary treatment for patellofemoral instability [16]. Nevertheless, there are no clear indications about lateral release in combination with acute MPFL reconstruction. The literature points to a scant of amount of comparative prospective studies comparing MPFL reconstruction with and without lateral release. However, when it comes to primary repair of the MPFL, a few clinical studies have shown increased recurrence rates of patellar instability when lateral release is added [12,17] and only one invitro study conducted by Bedi et al. investigated the effect of lateral release on patellar stability when an MPFL repair is performed [18]. Bedi et al. measured the force required to displace the patella $1 \mathrm{~cm}$ laterally in eight fresh-frozen human cadaveric knees when the MPFL was transected, upon repair, and then when lateral release was added. They noticed that lateral release reduced the required force by $7 \%$ to $11 \%$ compared with the MPFLrepaired knee. Their findings support the hypothesis that lateral release cannot be routinely performed in primary repair of the MPFL ligament for acute patellar instability. Thus, the role of lateral retinacular release in MPFL reconstruction surgery as the treatment for patellar instability should be investigated.

The aim of this study is to study the effect of lateral release after acute MPFL reconstruction using a previously validated patellofemoral finite element model [19]. As the lateral retinaculum has been shown to contribute to medial and lateral stabilization of the patella in knees with an intact MPFL [16], we hypothesize that performing a lateral release when performing MPFL reconstruction will alter the biomechanics of the patellofemoral joint and increase the lateral instability of patella. Understanding the biomechanics of this procedure will further help elucidate the best surgical approach for acute patellar dislocations.

\section{Methods \\ Conditions}

A previously developed and validated finite element (FE) model of the patellofemoral joint (PFJ) was used to simulate the conditions to understand the effect of lateral retinaculum release following MPFL reconstruction [19].

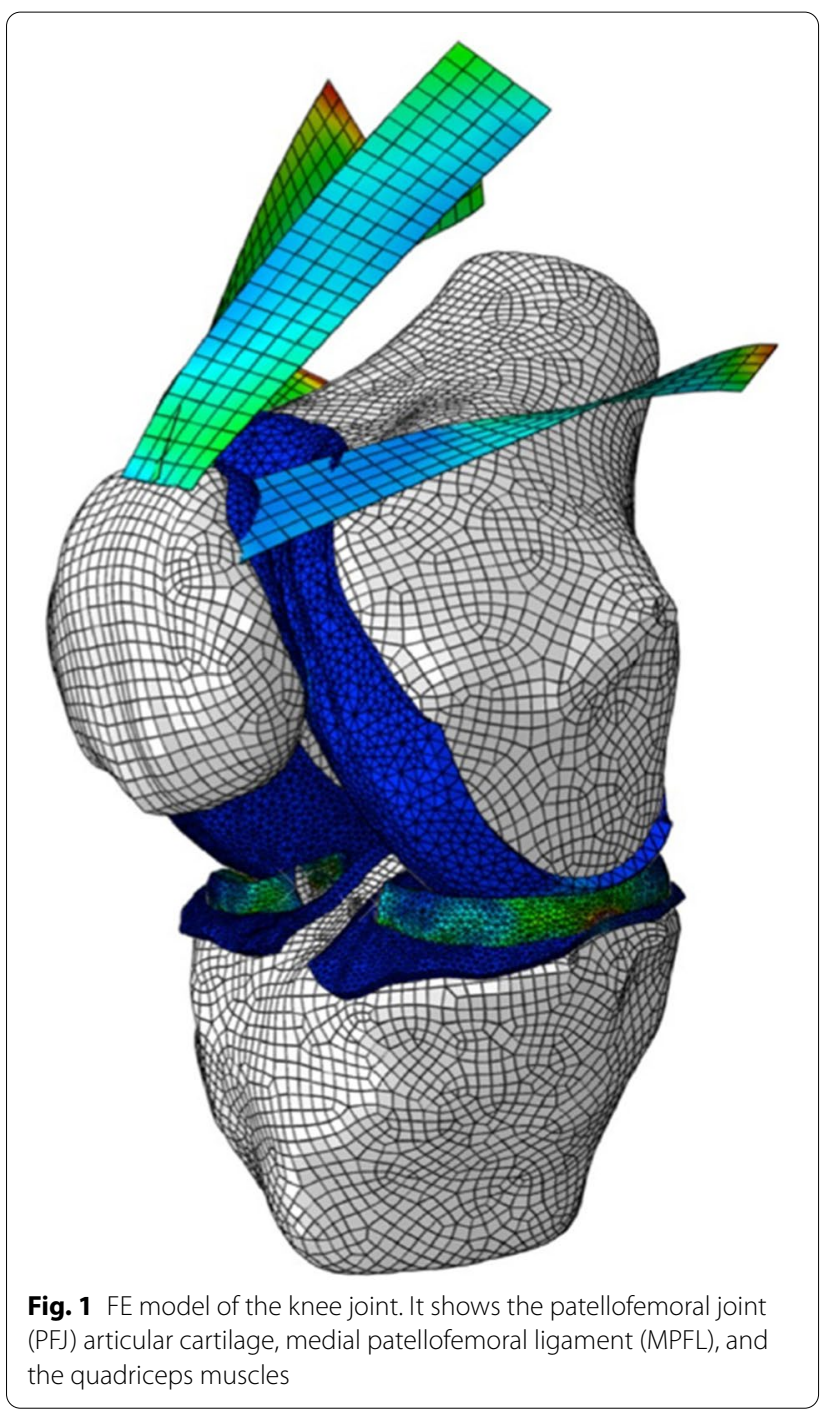

The FE mesh model is illustrated in Fig. 1. According to previous biomechanical studies, the following parameters were used in the FE model: a total load of $175 \mathrm{~N}$ was applied to the quadriceps muscle group, a load of $30 \mathrm{~N}$ to the iliotibial band, a stiffness of $49 \mathrm{~N} / \mathrm{mm}$ for the patellar tendon, a stiffness of $16 \mathrm{~N} / \mathrm{mm}$ for the MPFL and a stiffness of $97 \mathrm{~N} / \mathrm{mm}$ for the lateral retinaculum [20-23]. The quadriceps muscle was divided into five components represented by $2 \mathrm{D}$ quadrilateral mesh elements. The direction and tension of each component were taken from literature [16, 24]. Contact interactions between cartilage and cartilage, and cartilage and menisci were simulated using a frictionless finite-sliding formulation [25, 26].

The transepicondylar axis was used as axis of rotation to simulate knee flexion [27]. Femoral degrees-of-freedom and tibial medial-lateral translation and internal-external rotation were constrained; the remaining 
tibial degrees-of-freedom were left free. The patella was unconstrained for all six free degrees-of-freedom.

In addition to the healthy, intact condition with a TT-TG of $12 \mathrm{~mm}$, we created 3 variations of the model to sequentially examine patellar instability, MPFL reconstruction, and lateral release (Table 1).

The intact model was altered to simulate injury: spring elements representing MPFL were deactivated, since the MPFL is injured in the majority of patients after dislocation [3-7]. This injured model was then modified to simulate MPFL reconstruction: the MPFL spring elements were reactivated, but the stiffness was set to $20 \mathrm{~N} /$ $\mathrm{mm}$ which corresponds to the stiffness of the semitendinosus tendon (i.e., the tendon used for reconstruction) [28]. Finally, the reconstruction model was changed by deactivating the spring elements representing the lateral retinaculum in order to simulate lateral release. Contact pressure $(\mathrm{CP})$ and contact area $(\mathrm{CA})$ were recorded between the patella and the trochlear groove. The patellar kinematic (lateral displacement) were recorded relative in a $28 \%$ decrease of $\mathrm{CP}$ at $30^{\circ}$ and $45 \%$ at $90^{\circ}$ of knee flexion in the knee with lateral release. Interestingly at $60^{\circ}$ of knee flexion, the CP of the MPFL reconstruction with lateral release condition approximates that of the other conditions with only $4 \%$ difference.

\section{Contact Area}

Patellofemoral CAs of the different approximated by the FE model are illustrated in Fig. 3. The injured condition shows a reduced $\mathrm{CA}$ at all knee flexion angles with a maximum difference of $15 \%$ to the intact condition and a minimum of $3 \%$ difference only at $30^{\circ}$ of knee flexion. Reconstruction of the MPFL shows only a $1 \%$ increase in CA compared to the intact condition, with an $18 \%$ increase only at $15^{\circ}$. Performing a lateral release, following an MPFL reconstruction, results in a minimum decrease of $12 \%$ of $\mathrm{CA}$ at $15^{\circ}$ and a maximum of $44 \%$ decrease of $\mathrm{CA}$ at $60^{\circ}$ when compared to the intact condition. In addition, the MPFL reconstruction with lateral release showed a decrease of $27 \%$ of CA at $15^{\circ}$ and a $44 \%$

Table 1 Characteristics of investigated conditions in the FE model

\begin{tabular}{llll}
\hline Conditions & TT-TG $(\mathbf{m m})$ & MPFL & Lateral Retinaculum \\
\hline Healthy & 12 & MPFL stiffness/Intact & Native stiffness/Intact \\
Patellar Instability & 12 & Deactivated/Transected & Native stiffness/Intact \\
MPFL Reconstruction & 12 & Semitendinosus stiffness/Reconstructed & Native stiffness/Intact \\
MPFL Reconstruction + Lateral & 12 & Semitendinosus stiffness/Reconstructed & Deactivated/Transected \\
Resection & & & \\
\hline
\end{tabular}

to a standard reference of the intact knee at $0^{\circ}$ of flexion. PFJ CP, CA and lateral displacement were measured at $0^{\circ}, 5^{\circ}, 10^{\circ}, 15^{\circ}, 30^{\circ}, 60^{\circ}$, and $90^{\circ}$ of knee flexion for each tested condition.

\section{Results \\ Contact Pressure}

Patellofemoral CPs of the different conditions approximated by the FE model are illustrated in Fig. 2. The injured condition shows an $11 \%$ increase in contact pressure compared to the intact model at $30^{\circ}$ knee flexion angle before having equal contact pressure at $60^{\circ}$. The reconstruction of the MPFL most closely approximates the intact condition, with a $13 \%$ decrease in CP only at $15^{\circ}$. Performing a lateral release, following an MPFL reconstruction, results in lower $\mathrm{CP}$ throughout knee flexion with a difference of $27 \%$ at $30^{\circ}$ and $39 \%$ at $90^{\circ}$ of knee flexion respectively compared to the intact model. These differences are similar when comparing MPFL reconstruction with and without lateral release, which results decrease of $\mathrm{CA}$ at $60^{\circ}$ when compared with condition with only an MPFL reconstruction.

\section{Lateral Patellar Displacement}

Lateral patellar displacement of the different conditions approximated by the FE model are illustrated in Fig. 4. At knee flexion angles less than $15^{\circ}$, the lesion model increased the lateral patellar displacement by $20 \%$ compared to the rest of the conditions. Lateral release with MPFL reconstruction showed increased lateral patellar displacement compared to the other conditions starting at $20^{\circ}$ reaching a maximum increase of $21 \%$ at $60^{\circ}$ of knee flexion angle.

\section{Discussion}

The results from the FE model show that lateral retinacular release following MPFL reconstruction in knees with TT-TG of $12 \mathrm{~mm}$ have decreased CP, CA and increased lateral patellar displacement with increasing knee flexion. With decreasing $\mathrm{CP}$ and $\mathrm{CA}$, lateral release offloads the patella in the patellofemoral joint, which is why it 

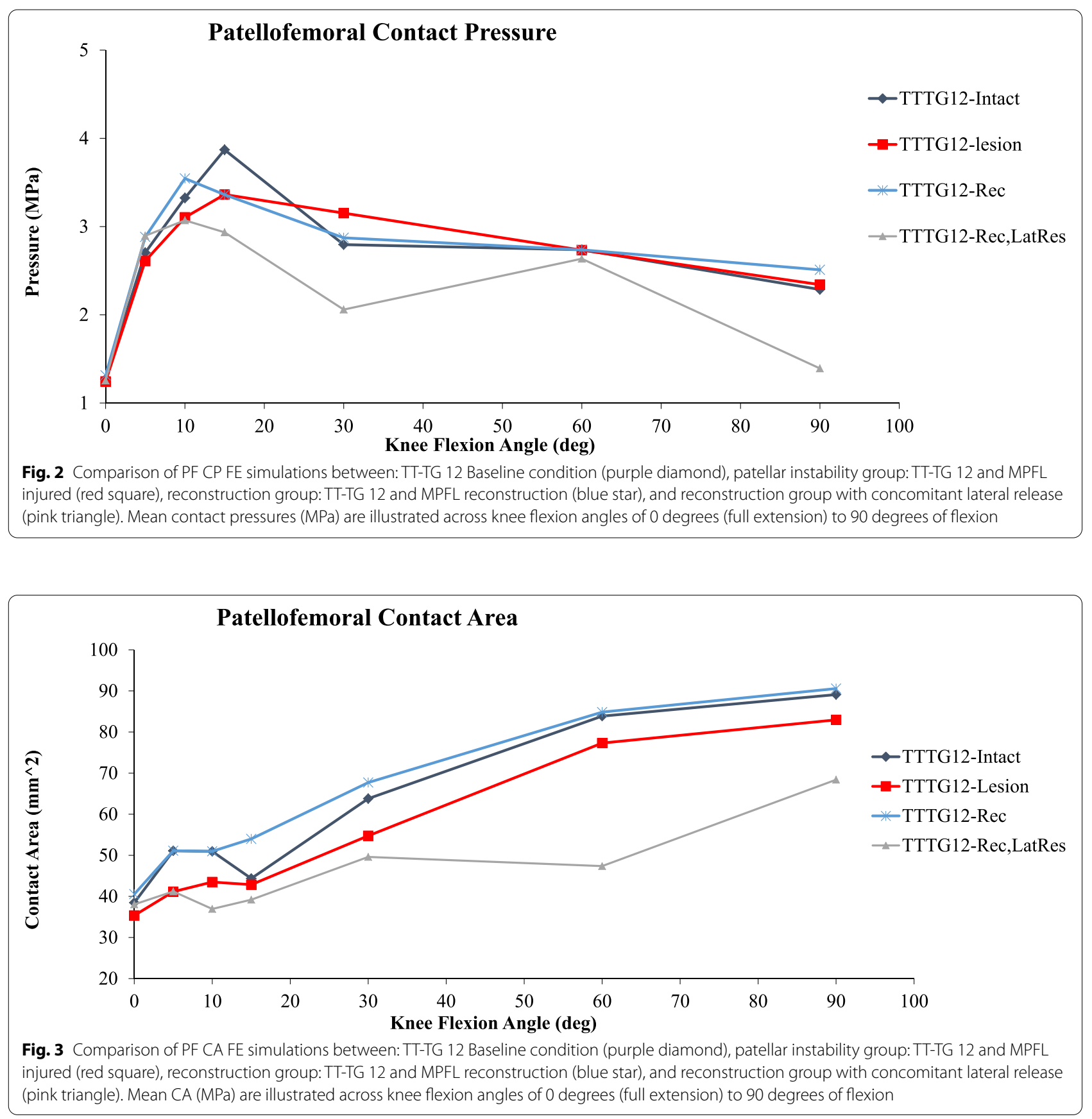

is advocated in patients suffering from lateral patellar compression syndrome [29]. However, the decrease in PF contact and increase in lateral patellar displacement following lateral release (LR) may increase the risk of patellar instability. This can explain the lesser amount of force needed to displace the patella laterally in the study by Bedi et al. [18]. In addition, using the same FE model, these results are in line with the results when lateral release is performed concomitantly with a tibial tuberosity osteotomy to treat patellar instability when the TT-TG distance is greater than $12 \mathrm{~mm}$ [19]. Thus, regardless of the procedure being performed for patellar instability, the addition of LR will decrease the patellofemoral joint CA, CP and increase the lateral patellar displacement.

Clear indications for the concomitant release of the lateral retinaculum during MPFL reconstruction surgery do not exist [30]. A systematic review done by Migliorini 


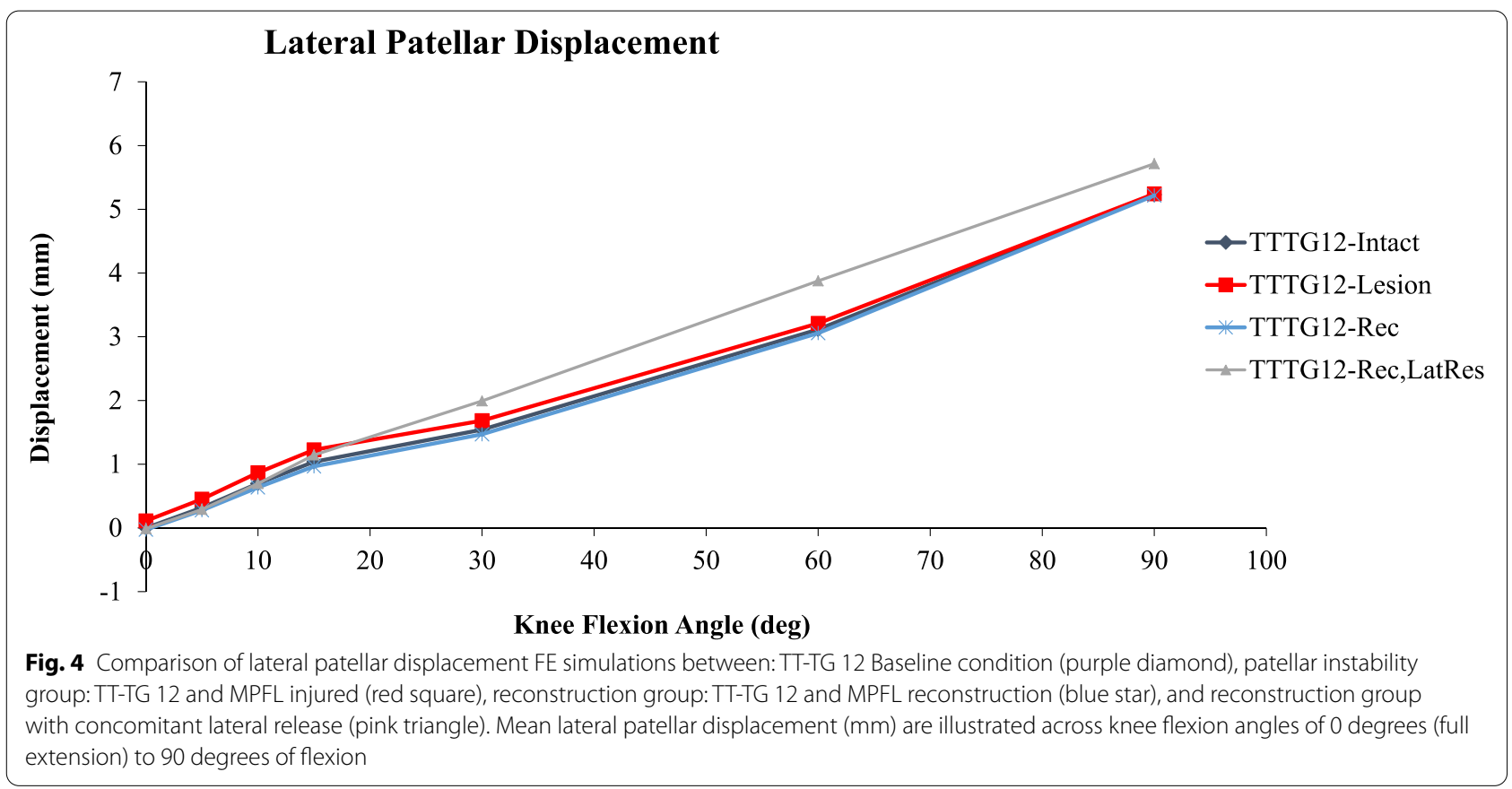

et al showed that some surgeons advocate concomitant release of the lateral retinaculum in all patients undergoing MPFL reconstructions, while others had various criteria on when it should be performed [30]. In the systematic review, it showed that patients that had lateral release had higher patient reported outcome measures (PROMs) compared to those that did not get a lateral release, but the results were not statistically significant [30]. These results are in parallel with Malatray et al that showed a non-statistically significant higher functional score in the lateral release group [31]. Migliorini et al hypothesized that the unloading mechanism of the lateral release on the lateral patellar compartment, which is injured in the majority of acute patellar dislocations [32], may be the contributing factor to the increased PROMs in patients with LRR [30]. As seen by the FE model, when a lateral release is performed during MPFL reconstruction, the CA and CP between the patella and trochlear groove decreases with increasing knee flexion. This decreased CA and CP confirm the hypothesis of Migliorini et al and can explain the increased PROMs in the patients that had a lateral release. However, this unloading mechanism of the lateral release has no effect on the development or progression of osteoarthritis, as outlined by Nomura et al, where after a mean follow-up of 11.9 years, osteoarthritis between patients that had an MPFL with and without a lateral release were the same [33].

The criteria for concomitant release of the lateral retinaculum during MPFL reconstruction surgery is heterogenous in nature and based on surgeon preference
[30]. Surgeons base their indication upon examination of the tension of the lateral structures and their effects on patellar maltracking post-MPFL reconstruction [30]. Han et al., on the other hand, advocates the use of lateral release in all patients undergoing MPFL reconstruction, stating that it improves post-operative range of motion [34]. In the FE model, it was shown that lateral release will cause increased lateral displacement in increasing knee flexions. Ultimately, this will lead to the conclusion of increased risk of lateral patellar instability. However, in the systematic review by Migliorini, the positive apprehension test and rates of dislocations amongst patients that had a lateral release and those that did not were similar [30]. In addition, in a prospective study conducted by Wang et al., where patients with MPFL reconstruction with and without LR were followed up for 1 year postoperatively, reported that the LR group had significantly better functional outcome scores and did not increase the risk of complications [35]. Thus, precise criteria for the use of lateral release need to be outlined in order to assist surgeons in the approach of the management of patients suffering from lateral patellar dislocation.

\section{Limitations}

The limitations of the study are related to the use of the FE model in stimulating the conditions needed to understand the role of lateral release in knees with MPFL reconstruction. The model used is based on a normal knee of which different conditions were applied on and it does not take into account other risk factors 
for patellar instability that include patella alta, trochlear dysplasia, and lateralization of the tibia tubercle. In addition, the FE model did not present patellar tilt. Not all patients with patellofemoral instability have patellar tilt, but for those with significantly abnormal patellar tilt on preoperative examination and radiographic studies, lateral release may be required for the patella to track normally. Finally, to reproduce MPFL reconstruction in this model, reactivation of the MPFL spring elements with use of the stiffness of the semitendinosus was done. However, variations in MPFL reconstruction surgery, which include the type of graft, number of bundles, and amount of graft tensioning, play a role in the outcome of the surgery of which the FE model does not take into account for.

\section{Conclusion}

In conclusion, this FE model showed that concomitant lateral retinaculum release with MPFL reconstruction results in decreased PF CA, CP and increased lateral patellar displacement with increased knee flexion, which may increase the risk of lateral patellar instability. Surgeons need to understand the biomechanical effects of lateral release on the PFJ during MPFL reconstruction and use it cautiously when indicated.

\section{Acknowledgements}

Not applicable

\section{Authors' contributions}

NK (data analysis and manuscript preparation); GS, AB, AO, JE, AM (data acquisition and analysis, manuscript prep); JPD, AJR, UGL, VD, and AN (study design, supervision, manuscript prep and approval). All authors read and approved the final manuscript.

\section{Funding}

No external source of funding was used.

\section{Availability of data and materials}

The data-sets used and/or analysed during the current study available from the corresponding author on reasonable request.

\section{Declarations}

Competing interests

The authors declare no competing interests.

\section{Ethics approval and consent to participate}

This article does not contain any studies with human participants or animals performed by any of the authors.

\section{Consent for publication}

All authors have provided their consent for the publication of this work.

\section{Competing interest}

The authors declare that they have no competing interests with this work.

\section{Author details}

${ }^{1}$ Musculoskeletal Translational Innovation Initiative, Carl J. Shapiro Department of Orthopaedic Surgery, Beth Israel Deaconess Medical Center, Harvard
Medical School, Boston, MA, USA. ${ }^{2}$ Department of Orthopaedic and Trauma Surgery, Campus Bio-Medico University, Rome, Italy. ${ }^{3}$ Clinical Research, Corin, Raynham, MA, USA. ${ }^{4}$ Carl J. Shapiro Department of Orthopaedic Surgery, Beth Israel Deaconess Medical Center, Harvard Medical School, Boston, MA, USA. ${ }^{5}$ Department of Orthopaedic Surgery, Yerevan State Medical University, Yerevan, Armenia.

Received: 13 October 2021 Accepted: 10 January 2022

Published online: 11 February 2022

\section{References}

1. Sillanpaa P, Mattila VM, livonen T, Visuri T, Pihlajamaki H. Incidence and risk factors of acute traumatic primary patellar dislocation. Med Sci Sports Exerc. 2008;40(4):606-11. https://doi.org/10.1249/MSS.0b013e3181 60740f PubMed PMID: 18317388.

2. Maenpaa $\mathrm{H}$, Huhtala $\mathrm{H}$, Lehto MU. Recurrence after patellar dislocation. Redislocation in 37/75 patients followed for 6-24 years. Acta Orthop Scand. 1997:68(5):424-6 PubMed PMID: 9385239.

3. Garth WP Jr., DiChristina DG, Holt G. Delayed proximal repair and distal realignment after patellar dislocation. Clin Orthop Relat Res. 2000;377:132-44. https://doi.org/10.1097/00003086-200008000-00019 PubMed PMID: 10943195 Epub 2000/08/16.

4. Kirsch MD, Fitzgerald SW, Friedman H, Rogers LF. Transient lateral patellar dislocation: diagnosis with MR imaging. AJR Am J Roentgenol. 1993;161 (1):109-13. https://doi.org/10.2214/ajr.161.1.8517287 PubMed PMID: 8517287 Epub 1993/07/01.

5. Nomura E. Classification of lesions of the medial patello-femoral ligament in patellar dislocation. Int Orthop. 1999;23(5):260-3. https://doi.org/10. 1007/s002640050366 (PubMed PMID: 10653289; PMCID: PMC3619764 Epub 2000/02/01).

6. Sallay PI, Poggi J, Speer KP, Garrett WE. Acute dislocation of the patella A correlative pathoanatomic study. Am J Sports Med. 1996;24(1):52-60. https://doi.org/10.1177/036354659602400110 (PubMed PMID: 8638754 Epub 1996/01/01).

7. Vainionpaa S, Laasonen E, Patiala H, Rusanen M, Rokkannen P. Acute dislocation of the patella. Clinical, radiographic and operative findings in 64 consecutive cases. Acta Orthop Scand. 1986;57(4):331-3 (PubMed PMID: 3788497).

8. Sillanpää PJ, Mäenpää HM. First-time patellar dislocation: surgery or conservative treatment? Sports Med Arthrosc Rev. 2012;20(3):128-35. https:/ doi.org/10.1097/JSA.0b013e318256bbe5 (PubMed PMID: 22878653 Epub 2012/08/11).

9. Ahmad CS, Stein BE, Matuz D, Henry JH. Immediate surgical repair of the medial patellar stabilizers for acute patellar dislocation. A review of eight cases. Am J Sports Med. 2000;28(6):804-10 (PubMed PMID: 11101102).

10. Nomura E, Inoue M. Injured medial patellofemoral ligament in acute patellar dislocation. J Knee Surg. 2004;17(1):40-6 (PubMed PMID: 14971674).

11. Sanders TG, Morrison WB, Singleton BA, Miller MD, Cornum KG. Medial patellofemoral ligament injury following acute transient dislocation of the patella: MR findings with surgical correlation in 14 patients. J Comput Assist Tomogr. 2001;25(6):957-62 (PubMed PMID: 11711811).

12. Dainer RD, Barrack RL, Buckley SL, Alexander AH. Arthroscopic treatment of acute patellar dislocations. Arthroscopy. 1988;4(4):267-71 (PubMed PMID: 3233116).

13. Halbrecht JL. Arthroscopic patella realignment: An all-inside technique. Arthroscopy. 2001;17(9):940-5. https://doi.org/10.1053/jars.2001.28980 (PubMed PMID: 11694925).

14. Longo UG, Berton A, Salvatore G, Migliorini F, Ciuffreda M, Nazarian A, Denaro V. Medial Patellofemoral Ligament Reconstruction Combined With Bony Procedures for Patellar Instability: Current Indications, Outcomes, and Complications. Arthroscopy. 2016;32(7):1421-7. https:// doi.org/10.1016/j.arthro.2016.01.013 (PubMed PMID: 27032603 Epub 2016/04/02)

15. Merican AM, Amis AA. Anatomy of the lateral retinaculum of the knee. J Bone Joint Surg Br. 2008;90(4):527-34. https://doi.org/10.1302/0301620X.90B4.20085 (PubMed PMID: 18378934).

16. Merican AM, Kondo E, Amis AA. The effect on patellofemoral joint stability of selective cutting of lateral retinacular and capsular structures. J 
Biomech. 2009;42(3):291-6. https://doi.org/10.1016/j.jbiomech.2008.11. 003 (PubMed PMID: 19135200).

17. Vainionpaa S, Laasonen E, Silvennoinen T, Vasenius J, Rokkanen P. Acute dislocation of the patella. A prospective review of operative treatment. J Bone Joint Surg Br. 1990;72(3):366-9 (PubMed PMID: 2341428).

18 Bedi H, Marzo J. The biomechanics of medial patellofemoral ligament repair followed by lateral retinacular release. Am J Sports Med. 2010;38(7):1462-7. https://doi.org/10.1177/0363546510373581 (PubMed PMID: 20601605 Epub 2010/07/06).

19. Salvatore G, Berton A, Orsi A, Egan J, Walley KC, Johns WL, Kheir N, Ramappa AJ, DeAngelis JP, Longo UG, Denaro V, Nazarian A. LATERAL RELEASE WITH TIBIAL TUBEROSITY TRANSFER ALTERS PATELLOFEMORAL BIOMECHANICS PROMOTING MULTIDIRECTIONAL PATELLAR INSTABILITY. Arthroscopy. 2021 https://doi.org/10.1016/j.arthro.2021.08.008 PubMed PMID: 34411682 Epub 2021/08/20

20. Kiapour A, Kiapour AM, Kaul V, Quatman CE, Wordeman SC, Hewett TE, Demetropoulos CK, Goel VK. Finite element model of the knee for investigation of injury mechanisms: development and validation. J Biomech Eng. 2014;136(1): 011002. https://doi.org/10.1115/1.4025692 (PubMed PMID: 24763546).

21. Balcarek P, Jung K, Frosch KH, Sturmer KM. Value of the tibial tuberositytrochlear groove distance in patellar instability in the young athlete. Am J Sports Med. 2011;39(8):1756-61. https://doi.org/10.1177/0363546511 404883 (PubMed PMID: 21566067).

22. Merican AM, Amis AA. lliotibial band tension affects patellofemoral and tibiofemoral kinematics. J Biomech. 2009;42(10):1539-46. https://doi.org/ 10.1016/j.jbiomech.2009.03.041 (PubMed PMID: 19481211).

23. Merican AM, Sanghavi S, Iranpour F, Amis AA. The structural properties of the lateral retinaculum and capsular complex of the knee. J Biomech. 2009;42(14):2323-9. https://doi.org/10.1016/j.jbiomech.2009.06.049. PubMedPMID:19647256:PMCID:2764350.

24. Farahmand F, Senavongse W, Amis AA. Quantitative study of the quadriceps muscles and trochlear groove geometry related to instability of the patellofemoral joint. Journal of orthopaedic research : official publication of the Orthopaedic Research Society. 1998;16(1):136-43. https://doi.org/ 10.1002/jor.1100160123 (PubMed PMID: 9565086).

25. McCann L, Ingham E, Jin Z, Fisher J. Influence of the meniscus on friction and degradation of cartilage in the natural knee joint. Osteoarthritis Cartilage. 2009;17(8):995-1000. https://doi.org/10.1016/j.joca.2009.02.012 (PubMed PMID: 19328878).

26. Orsi AD, Canavan PK, Vaziri A, Goebel R, Kapasi OA, Nayeb-Hashemi H. The effects of graft size and insertion site location during anterior cruciate ligament reconstruction on intercondylar notch impingement. Knee. 2017;24(3):525-35. https://doi.org/10.1016/j.knee.2017.02.010 (PubMed PMID: 28342722).

27. Churchill DL, Incavo SJ, Johnson CC, Beynnon BD. The transepicondylar axis approximates the optimal flexion axis of the knee. Clin Orthop Relat Res. 1998;356:111-8. https://doi.org/10.1097/00003086-19981100000016 (PubMed PMID: 9917674).

28. Saper MG, Meijer K, Winnier S, Popovich J Jr, Andrews JR, Roth C. Biomechanical Evaluation of Classic Solid and All-Soft Suture Anchors for Medial Patellofemoral Ligament Reconstruction. Am J Sports Med. 2017:45(7):1622-6. https://doi.org/10.1177/0363546517691951 (PubMed PMID: 28297604 Epub 2017/03/16).

29 Clifton $\mathrm{R}, \mathrm{Ng} \mathrm{CY}$, Nutton RW. What is the role of lateral retinacular release? J Bone Joint Surg Br. 2010;92(1):1-6. https://doi.org/10.1302/0301-620X. 92B1.22909 (PubMed PMID: 20044671 Epub 2010/01/02).

30. Migliorini F, Maffulli N, Eschweiler J, Quack V, Tingart M, Driessen A. Lateral retinacular release combined with MPFL reconstruction for patellofemoral instability: a systematic review. Arch Orthop Trauma Surg. 2021;141 (2):283-92. https://doi.org/10.1007/s00402-020-03689-9.

31. Malatray M, Magnussen R, Lustig S, Servien E. Lateral retinacular release is not recommended in association to MPFL reconstruction in recurrent patellar dislocation. Knee Surg Sports Traumatol Arthrosc. 2019;27(8):2659-64. https://doi.org/10.1007/s00167-018-5294-7 (PubMed PMID: 30483832 Epub 2018/11/30).

32 Nomura E, Inoue M, Kurimura M. Chondral and osteochondral injuries associated with acute patellar dislocation. Arthroscopy. 2003;19(7):71721. https://doi.org/10.1016/s0749-8063(03)00401-8 (PubMed PMID: 12966379 Epub 2003/09/11).
33. Nomura E, Inoue M, Kobayashi S. Long-term follow-up and knee osteoarthritis change after medial patellofemoral ligament reconstruction for recurrent patellar dislocation. Am J Sports Med. 2007;35(11):1851-8. https://doi.org/10.1177/0363546507306161 (PubMed PMID: 17724092 Epub 2007/08/29).

34. Han H, Xia Y, Yun X, Wu M. Anatomical transverse patella double tunnel reconstruction of medial patellofemoral ligament with a hamstring tendon autograft for recurrent patellar dislocation. Arch Orthop Trauma Surg. 2011;131(3):343-51. https://doi.org/10.1007/s00402-010-1173-5 (PubMed PMID: 20714901 Epub 2010/08/18).

35. Wang XL, Peng C, Tu YW, Liu YP, Zhang W, Zhang Y, Hua GJ. Effects of Lateral Patellar Retinaculum Release for Recurrent Patella Dislocation: A Prospective Study. Int J Gen Med. 2021;14:5527-35. https://doi.org/ 10.2147/ijgm.S329026 (PubMed PMID: 34531678; PMCID: PMC8439663. Epub 2021/09/18).

\section{Publisher's Note}

Springer Nature remains neutral with regard to jurisdictional claims in published maps and institutional affiliations.

Ready to submit your research? Choose BMC and benefit from

- fast, convenient online submission

- thorough peer review by experienced researchers in your field

- rapid publication on acceptance

- support for research data, including large and complex data types

- gold Open Access which fosters wider collaboration and increased citations

- maximum visibility for your research: over $100 \mathrm{M}$ website views per year

At BMC, research is always in progress.

Learn more biomedcentral.com/submissions 